\title{
Nephrocalcinosis in preterm neonates
}

\author{
Eveline A. Schell-Feith • Joana E. Kist-van Holthe • \\ Albert J. van der Heijden
}

Received: 6 March 2008 /Revised: 13 May 2008 / Accepted: 13 May 2008 /Published online: 17 September 2008

(C) IPNA 2008

\begin{abstract}
The prevalence of nephrocalcinosis (NC) in preterm neonates in recent reports is $7-41 \%$. The wide range in prevalence is a consequence of different study populations and ultrasound equipment and criteria, in addition to a moderate interobserver variation. $\mathrm{NC}$ in preterm neonates has a multifactorial aetiology, consisting of low gestational age and birth weight, often in combination with severe respiratory disease, and occurs as a result of an imbalance between stone-promoting and stoneinhibiting factors. A limited number of histological studies suggest that calcium oxalate crystals play an important role in $\mathrm{NC}$ in premature neonates. In $85 \%$ of children resolution of NC occurs in the first years of life. Prematurity, per se, is associated with high blood pressure, relatively small kidneys, and (distal) tubular dysfunction. In addition, NC in preterm neonates can have long-term sequelae for glomerular and tubular function. Long-term follow-up of blood pressure and renal function of prematurely born children, especially with neonatal $\mathrm{NC}$, is recommended. Prevention of $\mathrm{NC}$ with (low) oral doses of citrate has not resulted in a significant decrease in the prevalence of NC; a higher citrate dosage deserves further study. Future research pertaining to prevention of $\mathrm{NC}$ in preterm neonates is crucial.
\end{abstract}

E. A. Schell-Feith

Department of Pediatrics, Rijnland Ziekenhuis,

Leiderdorp, The Netherlands

J. E. Kist-van Holthe $(\bowtie)$

Department of Pediatrics, Leiden University Medical Center, Postbus 9600, 2300RC Leiden, The Netherlands

e-mail: j.kist@lumc.nl

A. J. van der Heijden

Department of Pediatrics, Erasmus MC-Sophia Children's Hospital, Rotterdam, The Netherlands
Keywords Nephrocalcinosis $\cdot$ Preterm neonate . Low birth weight $\cdot$ Renal ultrasound · Aetiology Follow-up · Prevention

\section{Introduction}

Nephrocalcinosis (NC), defined as renal calcification, was first described by Hufnagle et al. in 1982 in premature neonates who received long-term furosemide therapy [1].

$\mathrm{NC}$ in preterm neonates occurs as a result of imbalance between stone-promoting and stone-inhibiting factors. The aetiology of $\mathrm{NC}$ is multifactorial and comprehensive and will be discussed in detail.

As nephrogenesis is not completed until 34-36 weeks of gestation, the development of the kidneys, both anatomical and functional, is not completed at birth [2]. After birth, rapid changes in functional development occur. Injury to the kidneys in this period can affect renal function later in life [3]. There is growing evidence of an association of low birth weight with low nephron numbers and subsequent risk for adult cardiovascular disease and renal insufficiency [4]. However, full consensus has not been established, as recent studies do not fully support the hypothesis that low birth weight contributes to impaired kidney function, at least not until the age of 20-26 years [5, 6]. Nevertheless, development of $\mathrm{NC}$ in prematurely born children may carry an additional risk of compromising renal function later in life.

We will discuss prevalence, radiological and histological diagnosis, aetiology, natural course and long-term effects, in addition to prevention and treatment of $\mathrm{NC}$ in preterm neonates. 


\section{Prevalence of nephrocalcinosis}

$\mathrm{NC}$ is diagnosed in $7-64 \%$ of preterm neonates with gestational age $<32$ weeks or birth weight $<1,500 \mathrm{~g}$ [716]. The wide range in prevalence of $\mathrm{NC}$ is a consequence of different study populations and ultrasound equipment and criteria, in addition to a moderate interobserver variation [12]. Recent studies have noted a slightly lower prevalence of $7-41 \%$ than in the original reports $[12-16]$.

\section{Diagnosis of nephrocalcinosis}

Radiological evaluation

NC can be detected by conventional radiography, ultrasonography (Fig. 1) or computer tomography (CT). Ultrasonography is more sensitive than conventional radiography [17]. In rabbits with NC, ultrasound was more sensitive than CT (96\% vs 64\%), but CT was more specific than ultrasound (96\% vs $85 \%$ ) [18]. As CT involves a high radiation dose, it is unsuitable to detect $\mathrm{NC}$ in preterm neonates. Ultrasonography is a reliable method for screening and grading of young children with risk of $\mathrm{NC}$, with good intra- and interobserver agreement (kappa coefficient, respectively, 0.80 and 0.76) [19]. Reproducibility of ultrasound in detecting $\mathrm{NC}$ in preterm neonates has a very good intraobserver agreement (kappa 0.84), but a moderate interobserver agreement (kappa 0.46) [12]. NC was located exclusively in the medulla in more than $95 \%$ of kidneys [12].

However, increased medullary echogenicity in the preterm neonate is not exclusively found in $\mathrm{NC}$, but also in other conditions, such as renal candidiasis, cytomegalovirus infection, acute renal failure, polycystic kidney disease, renal vein thrombosis, or as a transient spontaneously resolving phenomenon of unclear aetiology in the first postnatal week [20-26].

\section{Histological evaluation}

$\mathrm{NC}$ is defined as mineral precipitates located in the renal parenchyma. Knowledge of the pathological aspects of the ultrasound findings in preterm neonates is scarce. Histological examination of a few kidneys of preterm neonates with medullary echogenicity showed calcifications, located either within the tubules or in the interstitium, consisting of calcium oxalate or calcium phosphate crystals $[1,10,27-$ 29]. Renal histology of 44 infants and neonates who had died after intensive care treatment between 1972 and 1992 was compared with that of 64 infants and neonates who had died without intensive care treatment [29]. Intratubular calcium oxalate deposits were found in eight of the intensive care-treated patients, whereas two of these cases
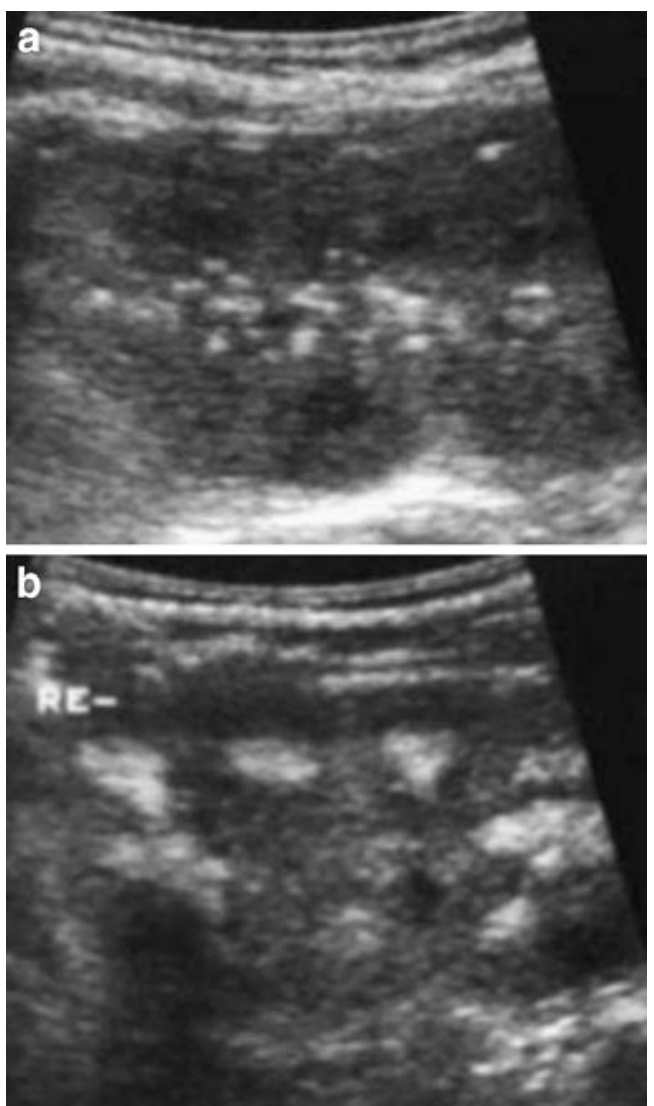

Fig. 1 a Renal ultrasound of a preterm neonate with moderate nephrocalcinosis, with small white flecks in the tip of the pyramids. $\mathbf{b}$ Ultrasound of kidney of a preterm neonate with severe nephrocalcinosis. White dots almost entirely fill the pyramids

in addition showed intratubular calcium phosphate deposits, which, in one patient, extended into the interstitium. The patients without intensive care treatment, on the other hand, demonstrated minimal calcium phosphate microliths in two cases, but no oxalate crystals. This suggests that calcium oxalate crystals play an important role in $\mathrm{NC}$ in intensive care-treated patients.

\section{Aetiology of nephrocalcinosis in preterm neonates}

$\mathrm{NC}$ in preterm neonates has a multifactorial aetiology, consisting of low gestational age and birth weight [1, 7-9, $13,14,30]$, often in combination with severe respiratory disease $[8,13,14,30,31]$, and it occurs as a result of an imbalance between stone-promoting and stone-inhibiting factors (Table 1). There is a clear correlation between prevalence of NC and low gestational age [7-9, 13, 14, 30]. Premature kidneys have relatively well-developed deep nephrons, with a long loop of Henle and probably low urine velocity. As a result, conditions are favourable for the formation of crystals, which can stick to the surface and 
Table 1 Aetiology of nephrocalcinosis in preterm neonates

\begin{tabular}{|c|c|}
\hline $\begin{array}{l}\text { Factors promoting } \\
\text { nephrocalcinosis }\end{array}$ & $\begin{array}{l}\text { Factors inhibiting } \\
\text { nephrocalcinosis }\end{array}$ \\
\hline $\begin{array}{l}\text { Hypercalciuria } \\
\text { acidosis } \\
\text { high calcium intake } \\
\text { low phosphorus intake } \\
\text { parenteral nutrition } \\
\text { medication } \\
\text { loop diuretics, methylxanthines, } \\
\text { vitamin D } \\
\text { glucocorticosteroid } \\
\text { Hyperoxaluria } \\
\text { high precursor intake } \\
\text { ascorbic acid, glycine } \\
\text { parenteral nutrition } \\
\text { secondary hyperoxaluria } \\
\text { fat malabsorption, } \\
\text { high phosphorus intake } \\
\text { Miscellaneous } \\
\text { Caucasian, male, family history } \\
\text { of kidney stones } \\
\text { nephrotoxic medication, } \\
\text { e.g. gentamicin }\end{array}$ & $\begin{array}{l}\text { Medication } \\
\text { thiazides } \\
\text { citrate } \\
\text { magnesium? } \\
\text { stone-inhibiting macromolecules } \\
\text { Osteopontin } \\
\text { Nephrocalcin? } \\
\text { Tamm-Horsfall protein? }\end{array}$ \\
\hline
\end{tabular}

grow and aggregate in the tubules. Under these circumstances stone-promoting factors such as hypercalciuria and hyperoxaluria, as described below, in combination with reduced stone-inhibiting factors like low urinary citrate excretion, can lead to NC.

Of course, other well-known causes of NC, such as primary hyperoxaluria, distal tubular acidosis, glucosegalactose malabsorption, Bartter's syndrome, Williams' syndrome, and hypophosphatasia, can also occur in preterm neonates [32-35]. Here, we will focus on NC of prematurity.

Factors promoting nephrocalcinosis

Factors promoting nephrocalcinosis are shown in Table 1.

\section{Hypercalciuria}

Mean urinary calcium/creatinine ratio in preterm neonates varies from $2.3-2.7 \mathrm{mmol} / \mathrm{mmol}$, which is much higher than reference values for term neonates and older children $(<0.6-0.9 \mathrm{mmol} / \mathrm{mmol}) \quad[30,36]$. On the other hand, considerable variation is reported, with much lower (median $0.31 \mathrm{mmol} / \mathrm{mmol}$ ) as well as much higher (mean $4 \mathrm{mg} / \mathrm{mg}=11.4 \mathrm{mmol} / \mathrm{mmol}$ ) values $[37,38]$.

Furosemide Several (early) studies indicated furosemide for chronic lung disease to be the most important aetiological factor in the development of NC in preterm neonates $[1,7$, 39]. Reabsorption of calcium in the loop of Henle is primarily passive, driven by the gradient created by sodium chloride $(\mathrm{NaCl})$ transport. Inhibition by furosemide of the $\mathrm{Na}^{+} \mathrm{K}^{+}-2 \mathrm{Cl}^{-}$carrier in the apical membrane leads to a parallel reduction in the reabsorption of calcium and, hence, to hypercalciuria [40]. In preterm neonates calciuresis may be prolonged due to slower plasma clearance [41, 42]. However, development of $\mathrm{NC}$ has also been described in preterm neonates without furosemide therapy $[8,43]$.

Glucocorticoids Many preterm neonates receive glucocorticoids for treatment or prevention of chronic lung disease [44-46]. High doses of glucocorticoids can lead to osteopenia, hypercalciuria and nephrolithiasis. The pathogenesis relates to an imbalance between resorption and formation of bone. An association between dexamethasone treatment, high calcium excretion and $\mathrm{NC}$ is, indeed, found in preterm neonates [13, 30, 47, 48].

Methylxanthines Caffeine and theophylline, both methylxanthines, are frequently prescribed to prevent apnoea in preterm neonates and are also known for their hypercalciuric effect. Urinary calcium excretion rose two- to tenfold in preterm neonates treated with methylxanthines in comparison with a control group [49, 50]. In keeping with this concept, a significant correlation was noted between theophylline prescription and $\mathrm{NC}$ in preterm neonates [30]. Suggested mechanisms to explain the hypercalciuria are increased diuresis and natriuresis, increased prostaglandin synthesis, and antagonism of adenosine-mediated effects with a change in renal blood flow and glomerular filtration rate $[49,51]$.

Acidosis Preterm neonates may experience periods of respiratory and/or metabolic acidosis. Acidosis results in a number of changes in adults that increase the risk of stone formation: increased urinary calcium as a result of bone buffering, decreased urinary citrate by increased reabsorption in the proximal tubule and decreased urinary $\mathrm{pH}$ [52]. Significantly more preterm neonates with NC show a tendency toward metabolic acidosis than those without $\mathrm{NC}[15]$.

Calcium intake As $80 \%$ of calcium and phosphorus accumulate in the fetus between the 25th post-conceptional week and full term, the majority of bone accumulation in preterm neonates takes place after birth [53]. Consequently, to prevent rickets of prematurity, the recommended intake of calcium (100-160 mg/kg per day) is high in comparison with that for full-term neonates [54]. High calcium intake is confirmed as a risk factor for $\mathrm{NC}$ in preterm neonates [30]. 
Vitamin D intake Vitamin D excess can result in hypercalcaemia and hypercalciuria. In order to prevent rickets, the intake of vitamin $\mathrm{D}$ in preterm neonates is relatively high. Recent guidelines advise an intake of 800-1,000 IU [54]. In spite of this, vitamin D has not been found to be a risk factor for NC. Vitamin D intake and vitamin 1,25 $(\mathrm{OH})_{2}$-vitamin $\mathrm{D}_{3}$ plasma levels were equal in preterm neonates compared with those without NC [30].

Phosphorus intake Recommended phosphorus intake for preterm neonates is $60-90 \mathrm{mg} / \mathrm{kg}$ per day and is like calcium intake, high in comparison with that for term neonates [54]. Phosphorus intake can influence the risk of developing $\mathrm{NC}$ in two ways.

Low intake of phosphorus can result in hypophosphataemia. Hypophosphataemia leads to a rise in phosphorus reabsorption in the proximal tubules, an increase in calcium and phosphorus absorption from the bone, and an increase in renal production of $1,25(\mathrm{OH})_{2}$-vitamin $\mathrm{D}_{3}$. Vitamin $\mathrm{D}$ stimulates the intestinal absorption and resorption of calcium and phosphorus from the bone. The consequent increase in serum calcium induces suppression of parathormone release, which results in a further decrease in urine phosphate and an increase in calcium excretion in adults [55]. In line with this hypothesis, Hein et al. confirmed that significantly more preterm neonates with NC had transient hypophosphataemia and hypercalciuria than did preterm neonates without NC [15]. In contrast Schell-Feith et al. did not find a difference in serum phosphate between preterm neonates with and without NC [30].

In contrast, a high intake of phosphorus is also associated with $\mathrm{NC}$ in preterm neonates [11, 30]. In addition, a high intake of phosphorus can lead to secondary hyperoxaluria, as will be explained later.

Sodium intake In children and adults sodium intake and excretion are linked to urinary calcium excretion and can result in hypercalciuria. Similarly, sodium excretion in preterm neonates is positively correlated with urinary calcium excretion [56]. Nonetheless, the correlation between sodium excretion and occurrence of $\mathrm{NC}$ in preterm neonates has not yet been studied.

Parenteral nutrition In preterm neonates on parenteral nutrition urinary calcium/citrate ratio increased in the first 10 days of life, while in human-milk-fed infants this ratio decreased, which indicates a higher risk of renal calcifications in preterm neonates fed parenterally [57]. Narendra et al. confirmed that $\mathrm{NC}$ occurs more frequently in preterm neonates with longer duration of parenteral nutrition [13], while Schell-Feith et al. could not find such a correlation [30].
Hyperoxaluria

As NC in preterm neonates can consist of calcium oxalate precipitates, high urinary excretion of oxalate might be an important factor in the development of NC [1, 29]. Hoppe et al. demonstrated that preterm neonates excrete more oxalate in the first months of life than do full-term neonates [58]. An association with higher urine oxalate/ creatinine ratio was found in preterm neonates with $\mathrm{NC}$ as opposed to those without NC by some [13, 59], but not by others [30].

Precursors of oxalate Ascorbic acid and glycine are precursors of oxalate. This could be the reason why preterm neonates receiving parenteral nutrition that contains ascorbic acid and glycine excrete higher urinary oxalate than do neonates receiving a glucose and electrolyte solution in the first week of life [60]. Formula-fed preterm neonates have a higher excretion of oxalate than do human milk-fed preterm neonates. This can be explained either by the fact that in formula for preterm neonates there is a higher concentration of ascorbic acid than in human milk, or by the mechanism of secondary hyperoxaluria, described below [61].

Secondary hyperoxaluria If calcium is bound to a compound in the gut, less calcium will be available for oxalate, and, therefore, oxalate will form complexes with sodium. In the intestines sodium-oxalate complexes are more readily absorbed than calcium-oxalate complexes. Thus, enteral oxalate absorption will increase and higher concentrations of oxalate will be excreted in the urine. One of these calcium-binding compounds in the gut is fat. Because fatty acid absorption is more effective in human milk-fed infants than in formula-fed infants, relative fat malabsorption can induce secondary hyperoxaluria in formula-fed neonates [61]. Moreover, phosphate can also form complexes with calcium in the gut and lead to secondary hyperoxaluria. In patients with hypophosphataemic rickets, high intake of phosphate has been described to lead to hyperoxaluria and $\mathrm{NC}$, even in a normocalciuric state [62].

Parenteral nutrition seems to increase not only urinary calcium/citrate ratio (see above), but also urinary oxalate excretion in preterm neonates. Therefore, parenteral nutrition may be an additional factor in the pathogenesis of nephrocalcinosis [57, 60].

\section{Miscellaneous}

Demographic characteristics NC occurs more often in Caucasians, male gender, and preterm neonates with a positive family history of kidney stones $[10,13]$. 
Nephrotoxic medication, e.g. gentamicin, has also been found to be a risk factor for NC in preterm infants [13].

Factors inhibiting nephrocalcinosis

Factors inhibiting nephrocalcinosis are shown in Table 1.

Citrate Citrate is an important chelator of calcium stones, because it forms complexes with calcium that are more soluble than calcium oxalate and calcium phosphate. Preterm neonates on mechanical ventilation had a low urinary citrate excretion when compared with a control group [63]. Schell et al. confirmed a lower urine citrate/ calcium ratio in preterm neonates with $\mathrm{NC}$ as opposed to those without NC [30]. Likewise, hypocitraturia was a major risk factor for $\mathrm{NC}$ in infants with very low birth weight, especially in those $<1,000 \mathrm{~g}$ [64]. In contrast, White et al. found similar values for urinary citrate in preterm neonates and healthy term babies. Furthermore, they found no association between urinary citrate and $\mathrm{NC}$ in preterm neonates [65]. A possible explanation for the lower excretion of citrate in some preterm neonates might be tubular reabsorption of citrate to compensate for episodes of respiratory and metabolic acidosis.

Magnesium Magnesium is another low molecular weight chelator, which forms complexes with oxalate that are more soluble than calcium oxalate. The role of urinary magnesium excretion in the development of $\mathrm{NC}$ has not been studied in preterm neonates.

Stone-inhibiting macromolecules Urine contains macromolecules, such as osteopontin, nephrocalcin and TammHorsfall protein, which can inhibit the processes of nucleation, agglomeration and growth in vitro [66]. Osteopontin, a glycoprotein originally identified as a component of bone, has been associated with a variety of functions, including mineralization, signalling and cell adhesion. The ability of osteopontin to bind and coat calcium oxalate crystals in renal tubules suggests that osteopontin may play a role in the prevention of renal calcium oxalate accumulation [38]. Urinary osteopontin concentration is significantly lower in premature neonates than in adults [38]. However, levels do not differ from those of term infants; therefore, interpretation of these lower values in the aetiology of $\mathrm{NC}$ is still under debate, and additional studies are warranted. On the other hand, expression of crystal-binding molecules (hyaluronan and osteopontin) at the luminal surface of the distal tubular cells in preterm neonates precedes crystal retention at the distal nephron epithelium, the first step to NC [67]. Nephrocalcin and Tamm-Horsfall protein have not been studied in preterm neonates.
Thiazides Thiazides, diuretics that inhibit sodium reabsorption in the distal tubules by blocking the thiazide sensitive $\mathrm{Na}^{+} \mathrm{Cl}^{-}$co-transporter, are frequently administered to preterm neonates with chronic lung disease. Thiazides decrease urinary excretion of calcium. This hypocalciuric effect can either be caused by an increase in proximal reabsorption of sodium and calcium in reaction to distal natriuretic effect of thiazides, or by a direct stimulatory effect of thiazides on the distal reabsorption of calcium. Nevertheless, Toffolo et al. have described preterm neonates with chronic lung disease who were treated with thiazides and developed NC anyway [43].

Animal model for nephrocalcinosis

In an animal model $\mathrm{NC}$ occurred within a few days of extremely high $(40 \mathrm{mg} / \mathrm{kg})$ furosemide administration in weanling rats. Interestingly, $\mathrm{NC}$ in this model was not age dependent but reflected a property of the loop diuretic itself [68].

\section{Natural course and long-term effects of nephrocalcinosis}

Nephrolithiasis

Rarely, urolithiasis is found in former preterms with severe NC. Downing et al. describes two patients who needed nephrolithotomy for ureteral obstruction [69]. That urolithiasis is not a frequent finding in $\mathrm{NC}$ is also suggested by a large prospective study, where none of the patients with $\mathrm{NC}$ developed urolithiasis during a 2-year follow-up period [70]. Haematuria is not a characteristic of patients with $\mathrm{NC}$, unless they have urolithiasis [70].

\section{Persistence of nephrocalcinosis}

In the majority of patients spontaneous resolution of $\mathrm{NC}$ occurs in the first years of life. However, persistence for several years has been described [11, 14, 69, 71-74]. In the largest ongoing study of preterm neonates, NC persisted in $34 \%, 15 \%$ and $10 \%$ after 15 months, 30 months and $7.4( \pm 1.0)$ years, respectively (Fig. 2) [70,75].

Long-term consequences

Long-term consequences are shown in Table 2.

\section{Blood pressure}

Although there is evidence that low birth weight is an important factor in the development of hypertension and the 


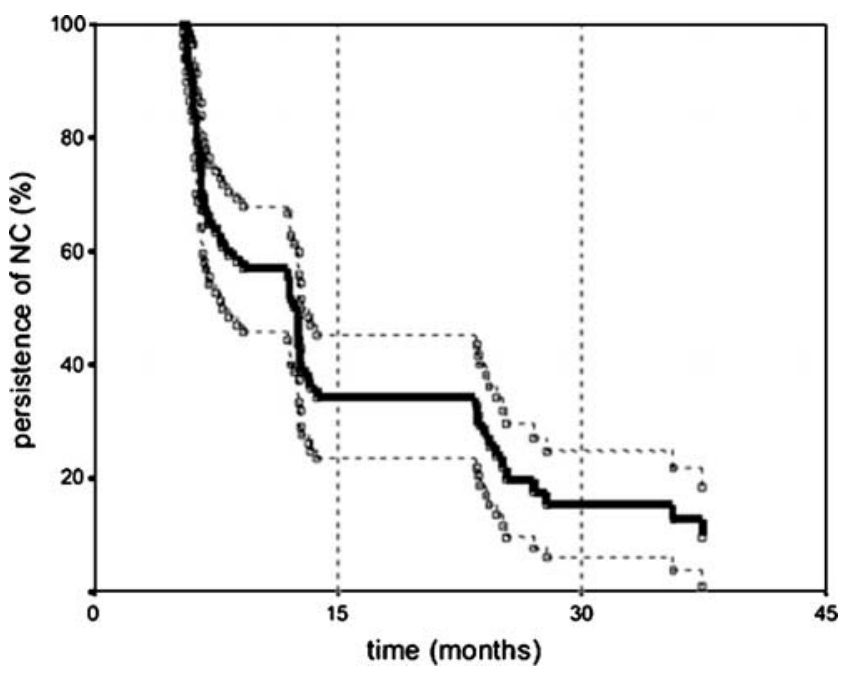

Fig. 2 Persistence of nephrocalcinosis (NC) with time, $n=70$ (continuous line) (95\% confidence interval dotted line) [70]

metabolic syndrome in adults, prematurity did, but birth weight standard deviation score (SDS) did not, predict hypertension in a large cohort of 19-year-old former preterms (Table 2) [76, 77]. Likewise, blood pressure of children born preterm with and without NC did not differ when they were a mean age of 7.4 years. However, it was significantly higher than expected for healthy children, although only a minority of former preterms with (3/42) and without $(2 / 31) \mathrm{NC}$ in fact had a systolic blood pressure $>95$ th percentile [75] (Table 2).

\section{Renal growth}

Decreased renal growth at the age of 20 years was noted in former preterms (gestational age $<32$ weeks) compared to full-term born controls [5]. Likewise, the kidneys of patients with and without neonatal NC were significantly smaller than expected for healthy children of the same height [75]. It is hypothesized that preterm neonates are specifically at risk of renal growth impairment because nephrogenesis peaks at 32 weeks and continues until 36 weeks. So far as limited evidence suggests, NC does not further impair renal growth.

Table 2 Possible long-term effects of nephrocalcinosis and prematurity per se (TRP tubular reabsorption of phosphate)

\begin{tabular}{ll}
\hline Nephrocalcinosis & Prematurity \\
\hline Decreased glomerular & Decreased glomerular \\
filtration rate & filtration rate \\
Low TRP & High blood pressure \\
(Distal) renal tubular acidosis & Decreased renal growth \\
Decreased concentrating & Decreased concentrating \\
capacity & capacity \\
Hypercalciuria & Hypercalciuria \\
\hline
\end{tabular}

\section{Glomerular function}

Undoubtedly, the most important question is: does $\mathrm{NC}$ in very prematurely born children affect renal function in the long term? Several (early) studies comprising a limited number of selected children with preterm $\mathrm{NC}$ demonstrated reduced glomerular filtration rate (GFR) when they were aged between 1 year and 5 years $[69,71,72]$. In a prospective follow-up study, after $7.4 \pm 1$ years, significantly more children with NC $(6 / 40,15 \%)$ had low GFR $(<85 \mathrm{ml} / \mathrm{min}$ per $1.73 \mathrm{~m}^{2}$ body surface area) than did healthy children, this in contrast to children without neonatal NC $(2 / 32,6 \%)$, Fig. 3. However, there was no significant difference in GFR or microalbuminuria between the groups. Furthermore, no correlation between persistence of NC and low GFR was found, but the number former preterms with persisting $\mathrm{NC}$ $(n=4)$ was small [75]. This is in contrast with results of a study by Saarela et al., who found no significant difference in GFR at a mean age of 4.7 years between 20 former preterms with and 20 without $\mathrm{NC}$ in the neonatal period [73]. Hoppe et al. and Porter et al. also observed normal

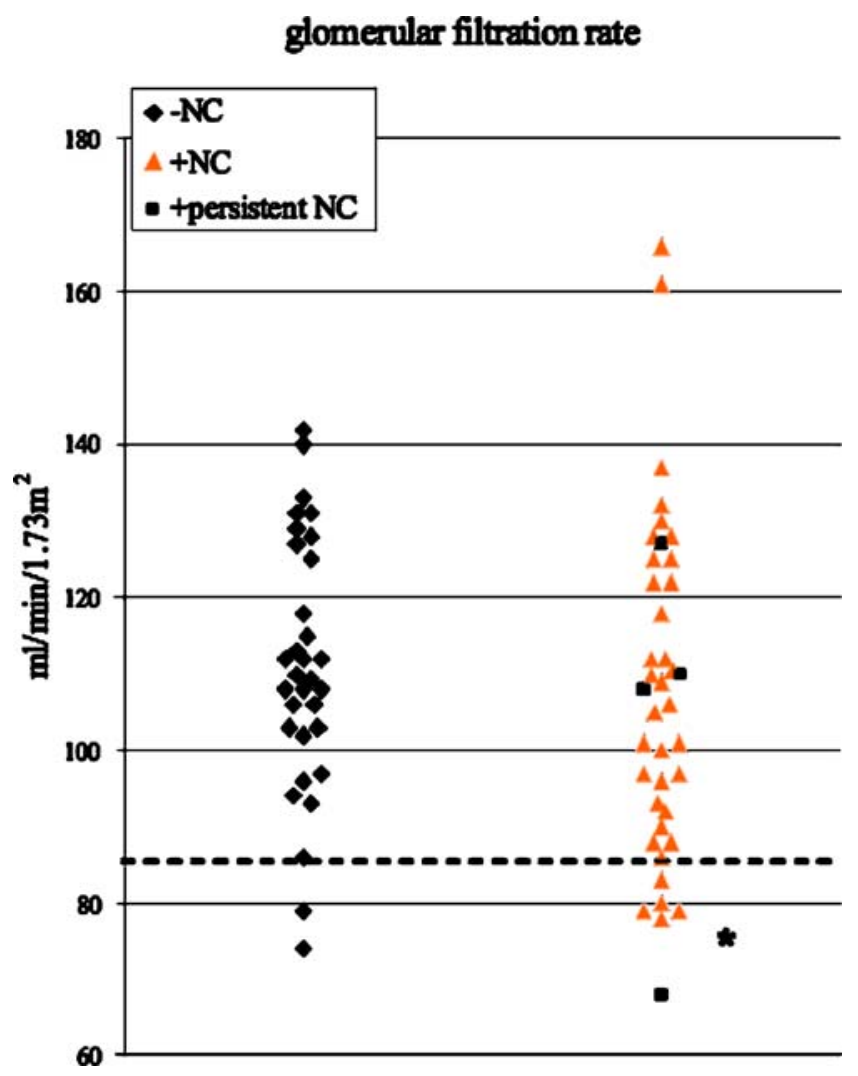

Fig. 3 Estimated GFR of former preterm infants with $(n=42)$ and without $(n=32)$ neonatal nephrocalcinosis at a mean age of 7.4 years. $+N C$ with nephrocalcinosis, $-N C$ without nephrocalcinosis. The asterisk indicates that significantly more children with neonatal nephrocalcinosis have (mild) chronic renal insufficiency than do healthy children, $P<0.0001$. The dashed line shows glomerular filtration rate $<85 \mathrm{ml} / \mathrm{min}$ per $1.73 \mathrm{~m}^{2}$ body surface area [75] 
GFR after 3-6 years and 5.8-7.7 years, respectively, in 12 and 14 prematurely born children with $\mathrm{NC}[14,74]$.

In conclusion, long-term follow-up of preterm neonates with $\mathrm{NC}$ demonstrates normal renal function in most patients. However, an unfavourable effect on renal function is seen in a small number of children.

\section{Proximal tubular function}

How does NC affect long-term tubular function? Jones et al. studied 11 former preterms when they were aged 45 years with neonatal NC. They found low median TmP/GFR (tubular maximum of phosphate reabsorption corrected for glomerular filtration rate) in comparison with reference values [71]. Likewise, Saarela et al. observed a significantly higher urine $\beta_{2}$-microglobulin/creatinine ratio in 20 children with $\mathrm{NC}$ than in 20 children without $\mathrm{NC}$ as preterm neonates, when they were a mean age of 4.7 years. However, in their study, tubular reabsorption of phosphate (TRP) did not differ significantly in children with and without $\mathrm{NC}$ [73]. In contrast, Downing et al. found significantly lower TRP ( $84 \pm 2 \%$ versus $93 \pm 1 \%$, normal value $>85 \%$ ) in former preterms at the age of 1-2 years with NC than in former preterms without NC [69]. Kist-van Holthe et al. also noted a significantly lower TRP in children with NC $(n=39)$ than in those without NC $(n=32)$ at a mean age of $7.4 \pm 1$ years. However, plasma phosphate was within normal limits in all children [75]. Therefore, the implication of low TRP in these patients is debatable. Glucosuria was not found in any of these children [75].

Considering these data, there is no firm evidence for proximal tubular dysfunction caused by neonatal $\mathrm{NC}$ in former preterms, with the exception of low TRP found in some patients (Table 2).

\section{Distal tubular function}

Downing et al. observed a lower ability to excrete hydrogen ions in the distal tubule in preterms with $\mathrm{NC}(n=10)$ than in those without NC $(n=14)$ [69]. Median plasma bicarbonate level was significantly lower in a larger study of children with $(n=42)$ and without $(n=32)$ neonatal NC. Urine anion gap of the children with low plasma bicarbonate levels was inappropriately high, indicating distal rather than proximal tubular dysfunction [75]. On the other hand, Hoppe et al. noted no acidosis after a follow-up period of 3-6 years in 12 former preterms with neonatal NC [14].

Most studies found no difference in early morning urine osmolality between former preterms with and without $\mathrm{NC}$ $[14,69,74,75]$. On the other hand, two studies demonstrated early morning urine osmolality to be significantly lower in former preterms than in healthy children [6, 71]. However, test results indicating impaired concentrating ability after desmopressin was found in $4 / 30$ children with neonatal $\mathrm{NC}$ at 1 year and in $2 / 25$ at 2 years [70]. In conclusion, $\mathrm{NC}$ in preterm neonates can have long-term sequelae, mainly for distal tubular acidification. Furthermore, some tubular defects (e.g. reduced early morning osmolality) cannot solely be attributed to NC but are also seen in former preterms without neonatal NC.

\section{Hypercalciuria}

Hypercalciuria is frequently seen in former preterms with neonatal NC. Significantly more $(9 / 41,22 \%)$ children with neonatal $\mathrm{NC}$ had hypercalciuria after a mean age of 7.4 years than expected for healthy children, in contrast to former preterms without $\mathrm{NC}(2 / 32,6 \%)$ [75]. This is in keeping with the findings of other smaller studies in which hypercalciuria with or without $\mathrm{NC}$ is described in former preterms (Table 2) [69, 71, 73, 74, 78].

\section{Prevention and treatment of nephrocalcinosis in preterm neonates}

In children with hypercalciuria, urinary calcium excretion decreases after administration of thiazides [79]. Nevertheless, a study in rats showed that, once established, NC caused by furosemide is not affected by thiazide therapy, in spite of its anti-calciuric effect [80]. The effect of thiazides on the natural course of $\mathrm{NC}$ in former preterm neonates has not yet been studied.

Children with primary hyperoxaluria have been treated successfully with sodium citrate [81]. Citrate supplementation in preterm neonates for prevention of $\mathrm{NC}$ from day 7 until term at a dose of $0.52 \mathrm{mmol} / \mathrm{kg}$ per day did decrease the urinary calcium/citrate ratio and was safe. Although a positive trend, no significant decrease in the prevalence of $\mathrm{NC}$ was found [82]. Prevention of $\mathrm{NC}$ with higher citrate dosage in preterm neonates deserves further study.

The balance between high intake of protein, phosphate, calcium and vitamin $\mathrm{D}$ for accretion of tissues on the one hand, and the risk of renal damage on the other hand, remains delicate, implying that, also in the newly developed guidelines for preterm neonates, attention to the development of $\mathrm{NC}$ is warranted.

\section{Summary}

Prevalence of $\mathrm{NC}$ of prematurity varied from $7-41 \%$ in the different populations studied. NC in preterm neonates has a multifactorial aetiology, consisting of low gestational age and birth weight, often in combination with severe respiratory disease, and occurs as result of an imbalance between 
stone-promoting and stone-inhibiting factors. Although spontaneous resolution of $\mathrm{NC}$ occurs in most children, some are at risk of renal damage later in life, validating the screening for $\mathrm{NC}$ of preterm neonates. Long-term follow-up of preterm neonates, especially with $\mathrm{NC}$, is warranted. Further research pertaining to prevention of NC is necessary.

\section{Questions}

(Answers appear following the reference list)

1. Nephrocalcinosis (NC) in preterm neonates is predominantly located in the
a. cortex
b. medulla
c. pyelocalyceal system
d. other

2. The mineral precipitates found in $\mathrm{NC}$ in intensive care treated neonates mainly consists of
a. intratubular calcium oxalate crystals
b. intratubular calcium phosphate crystals
c. interstitial calcium oxalate crystals
d. interstitial calcium phosphate crystals
e. all of the above

3. The aetiology of $\mathrm{NC}$ in preterm neonates is multifactorial. The following factor is important
a. low gestational age
b. high calcium and phosphate intake
c. severe respiratory disease
d. hypercalciuria
e. all of the above

4. Phosphate intake can influence the risk of developing

$\mathrm{NC}$ in the case of
a. high phosphate intake
b. low phosphate intake
c. normal phosphate intake
d. low as well as high phosphate intake

5. As a long term consequence(s) of $\mathrm{NC}$ in preterm neonates can be seen
a. haematuria
b. hypertension
c. decreased glomerular filtration rate
d. decreased renal growth

6. The most probable long-term outcome of $\mathrm{NC}$ in preterm neonates is
a. spontaneous resolution of $\mathrm{NC}$
b. decreased glomerular function
c. distal tubular dysfunction
d. persistence of $\mathrm{NC}$

7. High blood pressure in follow-up studies of neonates with $\mathrm{NC}$ is related to
a. severity of $\mathrm{NC}$
b. persistence of $\mathrm{NC}$
c. kidney growth
d. prematurity per se

\section{References}

1. Hufnagle KG, Khan SN, Penn D, Cacciarelli A, Williams P (1982) Renal calcifications: a complication of long-term furosemide therapy in preterm infants. Pediatrics 70:360-363

2. Chevalier RL (1996) Developmental renal physiology of the low birth weight pre-term newborn. J Urol 156:714-719

3. Rodriguez-Soriano J, Aguirre M, Oliveros R, Vallo A (2005) Long-term renal follow-up of extremely low birth weight infants. Pediatr Nephrol 20:579-584

4. Barker DJ (1990) The fetal and infant origins of adult disease. BMJ 301:1111

5. Keijzer-Veen MG, Kleinveld HA, Lequin MH, Dekker FW, Nauta J, de Rijke YB, van der Heijden BJ (2007) Renal function and size at young adult age after intrauterine growth restriction and very premature birth. Am J Kidney Dis 50:542551

6. Kistner A, Celsi G, Vanpee M, Jacobson SH (2000) Increased blood pressure but normal renal function in adult women born preterm. Pediatr Nephrol 15:215-220

7. Jacinto JS, Modanlou HD, Crade M, Strauss AA, Bosu SK (1988) Renal calcification incidence in very low birth weight infants. Pediatrics 81:31-35

8. Short A, Cooke RW (1991) The incidence of renal calcification in preterm infants. Arch Dis Child 66:412-417

9. Sheu JN, Chen CH, Lue KH, Chen JY, Tsau YK, Chen JH (1993) Renal calcification in very low birth weight infants. Am J Nephrol 13:6-11

10. Katz ME, Karlowicz MG, Adelman RD, Werner AL, Solhaug MJ (1994) Nephrocalcinosis in very low birth weight neonates: sonographic patterns, histologic characteristics, and clinical risk factors. J Ultrasound Med 13:777-782

11. Saarela T, Vaarala A, Lanning P, Koivisto M (1999) Incidence, ultrasonic patterns and resolution of nephrocalcinosis in very low birthweight infants. Acta Paediatr 88:655-660

12. Schell-Feith EA, Holscher HC, Zonderland HM, Kist-Van Holthe JE, Conneman N, van Zwieten PH, Brand R, van der Heijden AJ (2000) Ultrasonographic features of nephrocalcinosis in preterm neonates. Br J Radiol 73:1185-1191

13. Narendra A, White M, Rolton H, Alloub Z, Wilkinson G, McColl J, Beattie J (2001) Nephrocalcinosis in preterm babies. Arch Dis Child Fetal Neonatal Ed 85:F207-F213

14. Hoppe B, Duran I, Martin A, Kribs A, Benz-Bohm G, Michalk DV, Roth B (2002) Nephrocalcinosis in preterm infants: a single center experience. Pediatr Nephrol 17:264-268

15. Hein G, Richter D, Manz F, Weitzel D, Kalhoff H (2004) Development of nephrocalcinosis in very low birth weight infants. Pediatr Nephrol 19:616-620

16. Ketkeaw K, Thaithumyanon P, Punnahitananda S (2004) Nephrocalcinosis in very low birth weight infants: a single center experience. J Med Assoc Thai 87 [Suppl 2]:S72-S77

17. Alon U, Brewer WH, Chan JC (1983) Nephrocalcinosis: detection by ultrasonography. Pediatrics 71:970-973

18. Cramer B, Husa L, Pushpanathan C (1998) Nephrocalcinosis in rabbits - correlation of ultrasound, computed tomography, pathology and renal function. Pediatr Radiol 28:9-13

19. Dick PT, Shuckett BM, Tang B, Daneman A, Kooh SW (1999) Observer reliability in grading nephrocalcinosis on ultrasound examinations in children. Pediatr Radiol 29:68-72 
20. Shultz PK, Strife JL, Strife CF, McDaniel JD (1991) Hyperechoic renal medullary pyramids in infants and children. Radiology 181:163-167

21. Chiara A, Chirico G, Comelli L, De Vecchi E, Rondini G (1990) Increased renal echogenicity in the neonate. Early Hum Dev 22:29-37

22. Herman TE, Siegel MJ (1991) Pyramidal hyperechogenicity in autosomal recessive polycystic kidney disease resembling medullary nephrocalcinosis. Pediatr Radiol 21:270-271

23. Riebel TW, Abraham K, Wartner R, Müller R (1993) Transient renal medullary hyperechogenicity in ultrasound studies of neonates: is it a normal phenomenon and what are the causes? J Clin Ultrasound 21:25-31

24. Starinsky R, Vardi O, Batasch D, Goldberg M (1995) Increased renal medullary echogenicity in neonates. Pediatr Radiol 25 [Suppl 1]:S43-S45

25. Streitman K, Toth A, Horvath I, Tálosi G (2001) Renal injury in perinatal hypoxia: ultrasonography and changes in renal function. Eur J Pediatr 160:473-477

26. Makhoul IR, Soudack M, Smolkin T, Sujov P, Epelman M, Eisenstein I, Magen D, Zelikovic I (2005) Neonatal transient renal failure with renal medullary hyperechogenicity: clinical and laboratory features. Pediatr Nephrol 20:904-909

27. Downing GJ, Egelhoff JC, Daily DK, Alon U (1991) Furosemiderelated renal calcifications in the premature infant. A longitudinal ultrasonographic study. Pediatr Radiol 21:563-565

28. Karlowicz MG, Katz ME, Adelman RD, Solhaug MJ (1993) Nephrocalcinosis in very low birth weight neonates: family history of kidney stones and ethnicity as independent risk factors. J Pediatr 122:635-638

29. McCormick FC, Brady K, Keen CE (1996) Oxalate nephrocalcinosis: a study in autopsied infants and neonates. Pediatr Pathol Lab Med 16:479-488

30. Schell-Feith EA, Kist-van Holthe JE, Conneman N, van Zwieten PH, Holscher HC, Zonderland HM, Brand R, van der Heijden BJ (2000) Etiology of nephrocalcinosis in preterm neonates: association of nutritional intake and urinary parameters. Kidney Int 58:21022110

31. Woolfield N, Haslam R, Le Quesne G, Chambers HM, Hogg R, Jureidini K (1988) Ultrasound diagnosis of nephrocalcinosis in preterm infants. Arch Dis Child 63:86-88

32. Cumming WA, Ohlsson A (1984) Nephrocalcinosis in Bartter's syndrome. Demonstration by ultrasonography. Pediatr Radiol $14: 125-126$

33. Barcia JP, Strife CF, Langman CB (1997) Infantile hypophosphatasia: treatment options to control hypercalcemia, hypercalciuria, and chronic bone demineralization. J Pediatr 130:825-828

34. Mathias RS (2000) Rickets in an infant with Williams syndrome. Pediatr Nephrol 14:489-492

35. Pahari A, Milla PJ, van WG (2003) Neonatal nephrocalcinosis in association with glucose-galactose malabsorption. Pediatr Nephrol 18:700-702

36. Karlen J, Aperia A, Zetterstrom R (1985) Renal excretion of calcium and phosphate in preterm and term infants. J Pediatr 106:814-819

37. Giapros VI, Papaloukas AL, Andronikou SK (2007) Urinary mineral excretion in preterm neonates during the first month of life. Neonatology 91:180-185

38. Rockwell GF, Morgan MJ, Braden G, Campfield TJ (2007) Preliminary observations of urinary calcium and osteopontin excretion in premature infants, term infants and adults. Neonatology 93:241-245

39. Pope JC 4th, Trusler LA, Klein AM, Walsh WF, Yared A, Brock JW 3rd (1996) The natural history of nephrocalcinosis in premature infants treated with loop diuretics. J Urol 156:709-712

40. Rose B, Post T (2001) Clinical physiology of acid-base and electrolyte disorders, 5th edn. McGraw-Hill, New York, p 449
41. Mirochnick MH, Miceli JJ, Kramer PA, Chapron DJ, Raye JR (1988) Furosemide pharmacokinetics in very low birth weight infants. J Pediatr 112:653-657

42. Peterson RG, Simmons MA, Rumack BH, Levine RL, Brooks JG (1980) Pharmacology of furosemide in the premature newborn infant. J Pediatr 97:139-143

43. Toffolo A, Trevisanuto D, Meneghetti S, Talenti E, Zacchello G, Zanardo V (1997) Non-furosemide-related renal calcifications in premature infants with bronchopulmonary dysplasia. Acta Paediatr Jpn 39:433-436

44. Halliday HL, Ehrenkranz RA (2001) Delayed ( $>3$ weeks) postnatal corticosteroids for chronic lung disease in preterm infants. Cochrane Database Syst Rev CD001145

45. Halliday HL, Ehrenkranz RA (2001) Early postnatal ( $<96$ hours) corticosteroids for preventing chronic lung disease in preterm infants. Cochrane Database Syst Rev CD001146

46. Halliday HL, Ehrenkranz RA (2001) Moderately early (7-14 days) postnatal corticosteroids for preventing chronic lung disease in preterm infants. Cochrane Database Syst Rev CD001144

47. Kamitsuka MD, Williams MA, Nyberg DA, Fox KA, Lee DL, Hickok D (1995) Renal calcification: a complication of dexamethasone therapy in preterm infants with bronchopulmonary dysplasia. J Perinatol 15:359-363

48. Cranefield DJ, Odd DE, Harding JE, Teele RL (2004) High incidence of nephrocalcinosis in extremely preterm infants treated with dexamethasone. Pediatr Radiol 34:138-142

49. Zanardo V, Dani C, Trevisanuto D, Meneghetti S, Guglielmi A, Zacchello G, Cantarutti F (1995) Methylxanthines increase renal calcium excretion in preterm infants. Biol Neonate 68:169-174

50. Mazkereth R, Laufer J, Jordan S, Pomerance JJ, Boichis H, Reichman B (1997) Effects of theophylline on renal function in premature infants. Am J Perinatol 14:45-49

51. Gouyon JB, Guignard JP (1987) Renal effects of theophylline and caffeine in newborn rabbits. Pediatr Res 21:615-618

52. Rose B, Post T (2001) Clinical physiology of acid-base and electrolyte disorders, 5th edn. McGraw-Hill, New York, p 313

53. Tsang R, Lucas A, Uauy R, Zlotkin S (1993) Calcium, magnesium and vitamin D. In: Nutritional needs of the preterm infant: scientific basis and practical guidelines. Williams and Wilkins, New York, p 135

54. Rigo J, Pieltain C, Salle B, Senterre J (2007) Enteral calcium, phosphate and vitamin $\mathrm{D}$ requirements and bone mineralization in preterm infants. Acta Paediatr 96:969-974

55. Rose B, Post T (2001) Clinical physiology of acid-base and electrolyte disorders, 5th edn. McGraw-Hill, New York, pp 201-202

56. Bert S, Gouyon JB, Semama DS (2004) Calcium, sodium and potassium urinary excretion during the first five days of life in very preterm infants. Biol Neonate 85:37-41

57. Hoppe B, Hesse A, Neuhaus T, Fanconi S, Forster I, Blau N, Leumann E (1993) Urinary saturation and nephrocalcinosis in preterm infants: effect of parenteral nutrition. Arch Dis Child 69:299-303

58. Hoppe B, Hesse A, Neuhaus T, Fanconi S, Blau N, Roth B, Leumann E (1997) Influence of nutrition on urinary oxalate and calcium in preterm and term infants. Pediatr Nephrol 11:687-690

59. Berard E, Dageville C, Bekri S, Boutté P, Coussement A, Mariani R (1995) Nephrocalcinosis and prematurity: importance of urate and oxalate excretion. Nephron 69:237-241

60. Campfield T, Braden G (1989) Urinary oxalate excretion by very low birth weight infants receiving parenteral nutrition. Pediatrics $84: 860-863$

61. Campfield T, Braden G, Flynn-Valone P, Clark N (1994) Urinary oxalate excretion in premature infants: effect of human milk versus formula feeding. Pediatrics 94:674-678

62. Reusz GS, Latta K, Hoyer PF, Byrd DJ, Ehrich JH, Brodehl J (1990) Evidence suggesting hyperoxaluria as a cause of neph- 
rocalcinosis in phosphate-treated hypophosphataemic rickets. Lancet 335:1240-1243

63. Murphy JL, Mendoza SA (1990) Decreased urinary citrate in premature infants with lung disease. Child Nephrol Urol 10:76-80

64. Sikora P, Roth B, Kribs A, Michalk DV, Hesse A, Hoppe B (2003) Hypocitraturia is one of the major risk factors for nephrocalcinosis in very low birth weight (VLBW) infants. Kidney Int 63:21942199

65. White MP, Aladangady N, Rolton HA, McColl JH, Beattie J (2005) Urinary citrate in preterm and term babies. Early Hum Dev 81:319-323

66. Khan SR, Kok DJ (2004) Modulators of urinary stone formation. Front Biosci 9:1450-1482

67. Verhulst A, Asselman M, De Naeyer S, Vervaet BA, Mengel M, Gwinner W, D, Haese PC, Verkoelen CF, De Broe ME (2005) Preconditioning of the distal tubular epithelium of the human kidney precedes nephrocalcinosis. Kidney Int 68:16431647

68. Osorio AV, Alon MM, Nichols MA, Alon US (1998) Effect of age on furosemide-induced nephrocalcinosis in the rat. Biol Neonate 73:306-312

69. Downing GJ, Egelhoff JC, Daily DK, Thomas MK, Alon U (1992) Kidney function in very low birth weight infants with furosemide-related renal calcifications at ages 1 to 2 years. J Pediatr 120:599-604

70. Schell-Feith EA, Kist-van Holthe JE, van Zwieten PH, Zonderland HM, Holscher HC, Swinkels DW, Brand R, Berger HM, van der Heijden BJ (2003) Preterm neonates with nephrocalcinosis: natural course and renal function. Pediatr Nephrol 18:1102-1108

71. Jones CA, King S, Shaw NJ, Judd BA (1997) Renal calcification in preterm infants: follow up at $4-5$ years. Arch Dis Child Fetal Neonatal Ed 76:F185-F189

72. Ezzedeen F, Adelman RD, Ahlfors CE (1988) Renal calcification in preterm infants: pathophysiology and long-term sequelae. J Pediatr 113:532-539

73. Saarela T, Lanning P, Koivisto M (1999) Prematurity-associated nephrocalcinosis and kidney function in early childhood. Pediatr Nephrol 13:886-890

74. Porter E, McKie A, Beattie TJ, McColl JH, Aladangady N, Watt A, White MP (2006) Neonatal nephrocalcinosis: long term follow up. Arch Dis Child Fetal Neonatal Ed 91:F333-F336
75. Kist-van Holthe JE, van Zwieten PH, Schell-Feith EA, Zonderland HM, Holscher HC, Wolterbeek R, Veen S, Frolich M, van der Heijden BJ (2007) Is nephrocalcinosis in preterm neonates harmful for long-term blood pressure and renal function? Pediatrics 119:468-475

76. Keijzer-Veen MG, Finken MJ, Nauta J, Dekker FW, Hille ET, Frölich M, Wit JM, van der Heijden AJ, Dutch POPS-19 Collaborative Study Group (2005) Is blood pressure increased 19 years after intrauterine growth restriction and preterm birth? A prospective follow-up study in The Netherlands. Pediatrics 116:725-731

77. Barker DJ (1992) The fetal origins of adult hypertension. J Hypertens [Suppl 10]:S39-S44

78. Jones CA, Bowden LS, Watling R, Ryan SW, Judd BA (2001) Hypercalciuria in ex-preterm children, aged 7-8 years. Pediatr Nephrol 16:665-671

79. Reusz GS, Dobos M, Tulassay T, Miltényi M (1993) Hydrochlorothiazide treatment of children with hypercalciuria: effects and side effects. Pediatr Nephrol 7:699-702

80. Knoll S, Alon US (2000) Effect of thiazide on established furosemide-induced nephrocalcinosis in the young rat. Pediatr Nephrol 14:32-35

81. Leumann E, Hoppe B, Neuhaus T (1993) Management of primary hyperoxaluria: efficacy of oral citrate administration. Pediatr Nephrol 7:207-211

82. Schell-Feith EA, Moerdijk A, van Zwieten PH, Zonderland HM, Holscher HC, Kist-van Holthe J, van der Heijden BJ (2006) Does citrate prevent nephrocalcinosis in preterm neonates? Pediatr Nephrol 21:1830-1836

\section{Answers:}

1. b. medulla

2. a. intratubular calcium oxalate crystals

3. e. all of the above

4. d. low as well as high phosphate intake

5. c. decreased glomerular filtration rate

6. a. spontaneous resolution of $\mathrm{NC}$

7. d. prematurity per se 